San Jose State University

SJSU ScholarWorks

Faculty Publications

Social Work

January 2012

\title{
Parental problems, case plan requirements, and service targeting in child welfare reunification
}

Amy C. D'Andrade

San Jose State University, amy.dandrade@sjsu.edu

R. Chambers

California State University - Long Beach

Follow this and additional works at: https://scholarworks.sjsu.edu/social_work_pub

Part of the Social Work Commons

\section{Recommended Citation}

Amy C. D'Andrade and R. Chambers. "Parental problems, case plan requirements, and service targeting in child welfare reunification" Children and Youth Services Review (2012): 2131-2138. https://doi.org/ 10.1016/j.childyouth.2012.07.008

This Article is brought to you for free and open access by the Social Work at SJSU ScholarWorks. It has been accepted for inclusion in Faculty Publications by an authorized administrator of SJSU ScholarWorks. For more information, please contact scholarworks@sjsu.edu. 
RUNNING HEAD: Targeting Reunification Services

\author{
Parental Problems, Case Plan Requirements, \\ and Service Targeting in Child Welfare Reunification
}

Amy C. D'Andradea

Ruth M.Chambers ${ }^{b}$

a Corresponding author:

San Jose State University School of Social Work One Washington Square San Jose, CA 95192-0124 amy.dandrade@sjsu.edu

b California State University Long Beach School of Social Work 1250 Bellflower Boulevard Long Beach, CA 90840-4602

ruth.chambers@csulb.edu

Funding for this project came from the California Social Work Education Center (CalSWEC) and the California Department of Social Services. 


\begin{abstract}
Only about half of parents attempting to reunify with their children in foster care succeed in their efforts. Parents are ordered by the court to use treatment services in order to resolve their problems. These treatment services thus play a critical role in reunification, and in fact the use of services appropriately matched to parents’ problems has been found to be associated with a greater likelihood of reunification. However, there is little in the literature regarding the specific requirements of reunification case plans, and whether they are accurately targeted at reunifying parents' problems. This mostly descriptive study uses case file data to examine the relationship between parental problems and case plan requirements for a sample of parents reunifying with their children in one large urban California county. Findings show that most reunifying parents had multiple problems, and were required to attend approximately 8 service events per week. There was a positive correlation between the total number of concerns (treatment problems and life challenges) and required weekly service events. While $85 \%$ of parents were ordered treatment services for all their identified problems, over 30\% were ordered services targeting problems they were not known to have. Overall, 58\% of parents were ordered both all appropriate and only appropriate services. Implications for policy and practice are discussed, including the need for models of service delivery that limit the burden of accessing multiple service locations for reunifying parents.
\end{abstract}

Key words: Reunification, case plans, service matching. 


\section{Introduction}

When children are placed into foster care due to maltreatment, state case workers provide a case plan to parents detailing the services needed to resolve their problems. The Juvenile Court judge orders parents to access and use services within a specific time frame - usually six to twelve months - before their children can be returned to their care.

Improving the reunification rate is an important goal of the child welfare system. Only about half of parents succeed in their reunification efforts (Wulcyzn, 2004). According to the latest published report assessing state performance on federal child welfare outcomes, the median percentage of children reunified within 12 months from removal was just over 40\% (Childrens Bureau, n.d.). The most recent data from California shows a similar 12 month reunification rate, increasing to about $60 \%$ by 24 months and then leveling off (Needell et al., 2012).

Much of the research on reunification has focused on the association between demographic characteristics of parents and children with the likelihood of reunification. In recent years, an increasing number of researchers have focused on the services parents are ordered to use. Results suggest that use of certain types of services, such as family centered services (Lewandowski \& Pierce, 2004), recovery coaches (Ryan, Marsh, Testa \& Louderman, 2006) or substance use treatment (Green, Rockhill \& Furrer, 2007; Smith, 2003) are associated with an increased likelihood of reunification. However, we know surprisingly little about important aspects of reunification services and their use (Alpert, 2005). Neither reunification case plan requirements, nor the relationship between these requirements and parental problems have been well delineated in the research literature. 
This latter relationship is particularly important because if services on case plans are not well targeted to the parents' problems that contributed to the child's endangerment or injury, parents may not receive the services they need to resolve those problems. Indeed, research studies have shown that parents who received services that were "matched" to parental problems were more likely to reunify (Cheng, 2010; Choi \& Ryan, 2007). On the other hand, poorly targeted services may be viewed as irrelevant by reunifying parents, thus disinclining them from accessing those services. In Smith's (2008) qualitative study of 15 reunifying parents and case plan service compliance, some parents reported that the lack of relevance between their perceived needs and case plan requirements was a disincentive to compliance.

There is some reason to question the degree to which case plans are appropriately targeted: A number of states raised concerns in their federal Child and Family Service Review (CSFR) reports about reunification case plans following "boiler plate" templates that were not individualized for families' specific needs (CWIG, 2006). A recent institutional analysis of a public child welfare agency in one California county found that all reunifying parents were ordered almost identical case plans (Weber, Morrison, Navarro, Spigner \& Pence, 2010). The purpose of this study was to gain a better understanding of the relationship between the needs of reunifying parents and the types of reunification services to which they are ordered.

\subsection{Parents' treatment problems and life challenges.}

Certain common problems of reunifying parents such as substance use, domestic violence and mental health concerns tend to prompt orders for services specifically treating those problems. Studies of these treatment problems in the reunifying parent 
population studies generally find rates ranging from 36\%-79\% for substance use (Besinger, Garland, Litrowlik \& Landsverk, 1999; Marcenko et al., 2011; Wells \& Shafron, 2005), almost $40 \%$ for domestic violence (Marcenko et al., 2011); and just over 25\% for mental health problems (Wells \& Shafron, 2005).

A limited body of research explores the co-occurrence of substance abuse and other treatment problems in the reunifying parent population. Estimates of the co-occurrence of substance use and mental health problems in the reunifying parent population range from almost 15\% (Wells \& Shafran, 2005, as a barrier to employment) to 26\% (Marcenko et al., 2011); studies using samples consisting of substance-using reunifying parents have found higher rates varying from 50-60\% (Choi \& Ryan, 2007; Stromwall et al., 2008). Several studies have also considered the co-occurrence of domestic violence and substance use, and found rates varying from 32\%- 35\% (Choi \& Ryan, 2007; Smith \& Marsh, 2002 [sample includes child welfare involved parents, not just reunifying parents]). No studies were found that consider whether or how all three problems co-occur in the reunifying parent population.

Aside from substance use, domestic violence, and mental health problems, there are other issues confronting reunifying families, such as poverty, criminal justice involvement, housing instability, and health problems. Although less directly linked to parenting capacity and less likely to prompt court ordered services specifically targeting the particular concerns, these issues are likely to challenge or complicate parents' ability to access services and thus may reduce the family's chances of reunification. We refer to these conditions as "life challenges." 
These issues are prevalent in reunifying families. For example, a high proportion of reunifying families are poor. One study of a sample of 158 mothers whose children were placed in foster care found that $96 \%$ had annual incomes below the poverty level, and just over $80 \%$ were living in extreme poverty [at less than half the poverty level] (Wells \& Shafran, 2005); another study of 354 substance-using reunifying mothers found almost half had no income (Choi \& Ryan, 2007). Housing difficulties are also common: A study of 289 parents whose children were removed found that over $40 \%$ of the sample reported having to "move in with family or friends" (p. 404) within the last year, while about 30\% reported having been homeless within the last year (Courtney et al., 2004); in the Choi \& Ryan (2007) study almost $60 \%$ of the sample was identified as having "housing needs." In a New York study, $11 \%$ of a cohort of children entering foster care had mothers who were incarcerated while the case was open (Ross, Khashu \& Wamsley, 2004).

No studies were found that explored how reunifying parents' treatment problems and life challenges related to one another -- whether particular treatment problems are associated with particular life challenges, or more life challenges, than other treatment problems. This is an important consideration, both because these challenges may hinder a parent's ability to access and use services, but also because understanding how these problems co-occur may aid in developing more effective service delivery strategies.

\subsection{Case plan content and service targeting}

Research in the area of case plans and service requirements is scant (Ryan \& Schuerman, 2004; Smith, 2008). While reference to the general content of case plans was found ("Case plans typically require that parents complete substance abuse treatment, attend parenting classes, consistently attend visitations, meet with caseworkers, complete 
job training if needed, and have safe and stable housing" [Stromwall et al., 2008, p.99]), no studies were found that examined the details of reunification case plan requirements. One study articulated service plan requirements and recommended time allotment for a one intensive reunification program treating substance using clients. Requirements included substance abuse treatment services ( 9 hours per week), employment services ( 5 hours per week), case management (5 hours per week), parent training ( 2 hours per week) and other services (domestic violence counseling, family therapy, trauma counseling) (1-4 hours per week), for a total of 22-26 hours per week of service use (Brook \& McDonald, 2007).

There is a limited body of literature considering the issue of "service match" or service targeting in child welfare. In this study the term Service targeting is used to refer both to the degree to which treatment services are ordered for families with identified treatment needs, and the degree to which particular treatment services are not ordered for families who do not have the identified treatment need. There are three aspects of the process to consider: a) the particular problems parents have that need to be addressed, b) the treatment services parents are ordered to use, and c) parents' receipt of ordered services. One study of 488 families who received family preservation services examined the fit between b) services ordered or recommended and c) services received. The percentage of families who were did not receive recommended services varied between $27 \%-44 \%$ for concrete services, and between 17\%-22\% for clinical services (such as counseling, parenting training, substance use and mental health services) (Bagdasaryan, 2005). This study reveals the percentage of parents who receive the services to which they are ordered, but does not illuminate the issue of service targeting, as the nature of the parents' problems are not considered. 
Other studies have considered the fit between a) identified problem and c) services received, using a variety of strategies. Cash and Berry (2002) found correlations between identified needs such as transportation, unemployment, housing, and finances and receipt of associated concrete services, but other studies have found substantial gaps between identified needs and services received. Either no association was found between an identified need and receipt of related services (Ryan and Schuerman, 2004), or a relatively low percentage of clients (25-43\%) with an agency-identified or client-identified treatment need was provided related services (Choi \& Ryan, 2007; Smith \& Marsh, 2002). In another study child welfare-involved mothers were asked whether they received any of a set of 18 services; if the response was 'no,' mothers were asked if they needed the service. Reunifying mothers reported needing but not receiving physical and mental health (including parenting, substance use, domestic violence and mental health) at rates varying from 5\% to 38\% (Marcenko et al. 2011). These studies examine whether parents received services targeting their problems, but not whether the correct services were ordered. Parents may have failed to receive a service not because it wasn't ordered, but because the parents declined, or were unable, to use the service.

In order to understand whether services were appropriately targeted, the fit between a) identified problem and b) services ordered needs to be assessed. Findings from studies that considered targeting from this angle suggest a substantial portion of parents identified as having a particular problem are not ordered to receive services targeted at that problem. In a national study of 2100 child welfare-involved families (not exclusively reunification), only $78 \%$ of caregivers identified as having mental health problems were offered related services, and only about $66 \%$ of caregivers having substance use problems 
were offered substance use treatment services (Staudt \& Cherry, 2009). Antle et al. (2007) examining a systematically drawn sample of 100 cases from one state's neglect investigations found that only $36 \%$ of cases with domestic violence had treatment for domestic violence incorporated into the case plan (though 65\% had some kind of legal action taken related to the domestic violence, such as the filing of a restraining order against the perpetrator of the violence).

There is another important component of service targeting: whether families were ordered to receive services targeted at problems they were not known to have. This would suggest a "cookie-cutter" approach is being used to order services, rather than individualized assessment. No studies were found that examined service targeting from this angle for reunifying families. Additionally, with the exception of Choi \& Ryan (2007) and Marcenko et al. (2011), studies of service matching have examined families receiving family preservation services or investigated for maltreatment, not reunifying families.

Parental problems and life challenges, case plan requirements, and the relationship between them are important aspects of the reunification experience to understand if we hope to identify factors associated with service use and develop strategies to increase parents' use of reunification services. This descriptive quantitative study makes a beginning step toward exploring the issue by detailing parental problems and reunification case plan requirements for a sample of parents reunifying with children placed in foster care. The research questions pursued in the study are:

1. What are treatment problem and life challenges of reunifying parents?

2. What is the relationship between treatment problems and life challenges?

3. What are reunification case plan requirements for reunifying parents? 
4. What is the relationship between the number of case plan requirements and parental problems and life challenges?

5. How well targeted are services ordered for reunifying families?

\section{Methods}

\section{Research Design}

This primarily descriptive observational quantitative study examines the characteristics of parents attempting reunification with their children, the service requirements of their case plans, and the relationship of service requirements to parental problems and life challenges. Data on the characteristics of a cohort of parents were gathered from court reports written by case workers over the course of 3 years and from the agency administrative database; data on reunification services ordered were gathered from judicial orders filed in case files.

\section{Sample}

The population of interest was made up of the primary or custodial parents of children removed from home in one urban California county. To draw a sample representing this population, a group of children was identified that were 0-18 years of age, entered foster care in one urban California county between January 1, 2004 through December 31, 2004, and remained in foster care at least 7 days. A county data analyst provided a file from the child welfare administrative database with the designated population of children, and the primary investigator pulled a random sample of 200 from this population (after deleting siblings through a random selection process). Of the 200 cases, $24(12 \%)$ could not be located by county staff. Seventeen cases were found to be outside the parameters upon review (8.5\%), one case was too incomplete to use $(0.5 \%)$, 
and 13 cases (6.5\%) were removed due to parents' death, whereabouts unknown, or other reason rendering the case ineligible for the study. Of the 145 children remaining, 6 had parents who were not given reunification services and thus were excluded from the sample. The final remaining sample was 139 children; one parent of each child (mothers in the case of cohabitating parents; the custodial parent in the case of non-cohabitating parents) made up the observations for this study. Table 1 provides details on sample demographics. Almost half of parents in the sample were Latino; $36 \%$ were white. Ninetyfive percent were mothers. The average age of parents was just over 32, with a range from 17.5 to 53.5 .

-- Table 1 about here --

\section{Measures}

Data Source: For most variables, data came from court reports written by supervising case workers and judicial court orders stored in paper case files. In court reports, case workers describe the current circumstances of the child and parents, the services ordered, and the parent's progress and participation in services. For the variable of ethnicity, data came from the agency administrative database. As a general rule, the presence of a characteristic was not inferred; a characteristic was only coded as present if it was specifically noted as present by the case worker in the court report.

Demographics: Race was coded as African American, Asian, Caucasian, Hispanic/Latino, or Native American. Age was measured in years as an interval variable. Gender was a dichotomous variable.

Treatment Problems: Problems that prompted orders for specific services treating those problems were categorized as "treatment problems." In this study, these problems - 
Substance Use, Domestic Violence, and Mental Health Problem - were measured as

dichotomous variables indicating that either the case worker had noted the parent had the condition at the time of the child's removal from care, or that the condition emerged or was identified later in the case as noted by workers in subsequent court reports.

To understand the constellation of treatment problems experienced by reunifying parents, a categorical variable Problem Constellation was created, with each of the eight possible problem constellations as mutually exclusive and exhaustive answer options: 1 ) substance use only; 2) mental health problem only; 3) domestic violence only; 4) substance use and domestic violence; 5) substance use and mental health problem; 6) mental health and domestic violence; 7) substance use, mental health problem and domestic violence; or 8) no problems. This approach allows an understanding of the number of treatment problems parents have, as well as the co-occurrence of problems. A similar approach was used by Wells \& Shafron in their 2005 study to understand employment barriers of various types for reunifying mothers.

Life Challenges: Problems that did not prompt orders for specific services were categorized as "life challenges." (Judicial orders sometimes included statements like "parent is to obtain housing" or "parent to find employment", but such statements did not include referrals to specific services.) Housing Instability and Serious Health Issues were measured with dichotomous variables, with the condition coded as present if the researcher interpreted the parents' circumstances described by the social worker as reflecting the named condition at the time of the child's removal or later in the case as noted in subsequent court reports. Unemployment and Incarceration were measured with dichotomous variables, with the condition coded as present if the social worker indicated 
the parent experienced the condition at the time of the child's removal or later in the case as noted in subsequent court reports.

Count variables: Total Treatment Problems was a count variable representing the number of treatment problems confronting the parent, with a possible range from $0-3$. Total Life Challenges was a count variable representing the total number of Life Challenges confronting the parent, with a possible range from 0-4. Total Concerns was a count variable reflecting the sum of Total Life Challenges and Total Treatment Problems, with a possible range from $0-7$.

Services Ordered: Services ordered were dichotomous variables representing each type of service ordered for parents by the judicial officer at the dispositional or a subsequent court hearing over the three years covered by the study. These included parenting classes ("Basic," “Advanced," "Parenting without Violence”, or "other type”); domestic violence services (domestic violence assessment, "Batterers Program" and "Victims Program"); substance use services (substance use assessment, drug testing, inpatient treatment, outpatient/day treatment, 12-Step program, aftercare program, and "other type"); and mental health services (a psychological evaluation, medication or medication monitoring, a psycho-educational group, or some other psychological treatment). Counseling services of individual, family and couples counseling were considered distinct from mental health services, as these services were offered to almost all reunifying parents in this county. Orders for the parent to obtain housing or employment were not included as no specific service or attendance requirement was indicated. Visitation, while not a "service" per se, was included as it was ordered with specific attendance requirements on the case plan. 
Number of Services Ordered was a count of total services ordered for a parent, including one-time services of psychological evaluations, substance use and domestic violence assessments.

Weekly Service Events (WSE) was a count of the number of service events per week in which each parent would be required to participate in order to fully comply with his or her case plan. For example, a parent whose case plan requirements consisted of weekly parenting classes, weekly counseling sessions, twice weekly drug testing, and twice weekly visitation would have a Weekly Service Event score of 6. One-time service events (orientation, psychological evaluations, substance use assessments, domestic violence assessments) were not included in the count; also excluded was medication or medication monitoring, a service event that required only occasional attendance, and inpatient substance use treatment, as presumably this occurred where the parent resided and required no additional "attendance." When the weekly attendance requirement was not specified, or was specified in hours rather than number of times per week, we used a conservative estimate of once per week, even if the average attendance ordered for the service across the sample was more than one time per week. For parenting, counseling, and domestic violence treatment, weekly attendance in that county was the norm (M. Selassie, personal communication).

\section{Data collection and analyses procedures}

A human subjects protocol was approved by the university internal Institutional Review Board, and county agency approval as well as judicial court approval was received prior to data collection. A data collection instrument was drafted based upon instruments used in similar studies. A pilot test was conducted using approximately five cases from the 
same county. The primary researcher and two research assistants reviewed several cases each using the preliminary version of the data collection instrument. Several questions were reworded or adjusted as a result.

Data collection was done by the Principal Investigator and four student research assistants using the paper data collection instrument. Research assistants were provided with two days of training on child welfare procedures, case files, court reports, and data collection. All coders signed oaths of confidentiality. Coding rules were established prior to data collection, and coders were provided with written guidelines detailing these rules. County personnel pulled files and made them available to researchers. Researchers reviewed files and collected data on the data collection forms. Data were entered into SPSS.

Reliability was tested by having all five researchers review the same two cases, and comparing coders' answers for all variable formats except for open-ended qualitative questions. After each reliability case test, areas of discrepant coding were discussed and clarified. A pre-defined acceptable level of reliability was set at $80 \%$ (4 of 5) coders answer $85 \%$ of all questions identically. This level was met prior to data collection.

Univariate descriptive statistics were used to answer research questions 1, 3 and 5. Chi-square tests were run to test associations between the presence of individual treatment problems and life challenges, and independent samples t-tests were run to test associations between the presence of individual treatment problems and the number of life challenges for research question 2. Independent samples t-tests were also used to test associations between the presence of individual treatment problems and WSE, a Spearman's Rho was run to test the relationship between the number of treatment problems and WSE, and a Pearson correlation was run to test the relationship between the 
number of total concerns (treatment problems and life challenges) and WSE, all for research question 4 .

\section{Results}

\section{RQ 1: What are treatment problems and life challenges of reunifying parents?}

Substance use was the most common treatment problem experienced by reunifying parents. Three-quarters of parents in this sample (75.8\%) had a substance use problem, while just over 30\% experienced domestic violence, and just over one quarter had a mental health problem. The average number of treatment problems was $1.33(\mathrm{sd}=.80)$. Many parents were also experiencing other life challenges in addition to treatment problems. Over $40 \%$ of parents in this sample experienced incarceration, over $30 \%$ experienced housing instability, and a smaller but substantial proportion of parents had serious health problems or were unemployed. The average number of life challenges was 1.13 ( $\mathrm{sd}=.90)$. The average number of total concerns (treatment problems and life challenges combined) was $2.46(\mathrm{sd}=1.36)($ see Table 2$)$.

-- Tables 2 about here -

The most common treatment problem constellation was the sole problem of substance use (over one-third of parents were in this category). The next most common constellation was both a substance use and a domestic violence problem (almost 20\% of parents) and both a substance use and a mental health problem (about 15\% of parents). Interestingly, the next largest group of parents had none of these problems (see Table 3).

-- Table 3 about here --

\section{RQ2: What is the relationship between treatment problems and life challenges?}


We tested whether the presence of each treatment problem was associated with different rates of each life challenge. Parents with the problem of substance use had higher rates of each life challenge than did parents without the problem; differences between rates of housing stability and incarceration between parents with and without substance use problems were substantive and statistically significant. Parents with domestic violence issues had a substantially higher rate of housing instability than parents without domestic violence issues; parents with mental health problems had a higher rate of serious health problems than parents without mental health problems (see Table 4).

-- Table 4 about here --

We also tested whether the average number of life challenges varied by the presence of each treatment problem. The average number of life challenges is substantially higher for substance abusing parents than for non-substance abusing parents (1.33 vs. $0.52 ; t=4.89, \mathrm{df}=133, \mathrm{p}<.001)$. The average number of life challenges for parents with mental health and domestic violence is slightly higher than for parents without those problems, but the difference is not statistically significant (1.26 vs. 1.08 for parents with and without domestic violence issues; $t=1.11, \mathrm{df}=133, \mathrm{p}=.269 ; 1.17$ vs. 1.12 for parents with and without mental health problems; $\mathrm{t}=0.27, \mathrm{df}=133, \mathrm{p}=.797$ ).

\section{RQ3. What are reunification case plan requirements for reunifying parents?}

Some services were ordered for almost all parents. The most commonly ordered specific treatment service was individual counseling, with almost $90 \%$ of parents ordered to this service; drug testing was next, for almost $80 \%$ of parents; and 12 step program attendance was next most common, ordered for almost 70\% of parents. Almost all parents 
were ordered to receive some form of parenting class, and to visit their child in care. The percentage of parents ordered to receive each service is shown in Table 5.

-- Table 5 about here --

Parents were ordered to receive an average of 7.5 different services on their reunification case plans $(S D=2.13$, range $=1-12)$. Most were ordered to use between 4 and 9 services, with about $10 \%$ ordered to receive more, and about $10 \%$ less than this. For visitation, drug testing, and 12-step meetings, the court order often specified the number of times per week the parent was to attend the service. Table 6 shows per week attendance ordered for each of these services. Almost half of parents were ordered to visit their children twice or more times per week; about three-quarters of parents ordered to drug test or to attend 12 step meetings were ordered to do so twice or more often per week. The average Weekly Service Event (WSE) count (incorporating weekly attendance

requirements) was just under 8 service events per week $(\mathrm{m}=7.9, \mathrm{SD}=2.76$, range $=2-14)$.

-- Table 6 about here --

\section{RQ 4: What is the relationship between the number of case plan requirements and parental problems and life challenges?}

To understand the relationship between the number of case plan requirements and parents' problems and challenges, we first considered whether WSE varied by individual treatment problem. Parents with substance use problems had a higher average WSE than did parents without substance use problems, as two of the three services with multiple per week attendance requirements were substance use treatment services. On average, parents with substance use problems had an average WSE of 8.97, compared to 4.77 for parents without substance use problems $(\mathrm{t}=12.94, \mathrm{df}=94.39 ; \mathrm{p}<.001)$. Parents with domestic 
violence issues had a somewhat higher WSE than parents without domestic violence issues (8.98 compared to $7.43 ; \mathrm{t}=3.14 ; \mathrm{df}=135, \mathrm{p}=.002$ ) but there was no difference in WSE for parents with and without mental health problems (8.07 vs. $7.84 ; \mathrm{t}=0.42, \mathrm{df}=136, \mathrm{p} .=.674$ ).

We next considered whether WSE varied by problem constellation. Four categories of problem constellations had relatively low WSE: no treatment problem noted, a domestic violence problem or a mental health problem only, or domestic violence and mental health but no substance use problem. WSE for parents in these groups varied from 4.00 to 4.88 . For the other constellations, all of which include a substance use problem, the average WSE ranged from 8.41 (for those parents with only a substance use problem) to 10.50 (for those parents with all three problems) (see Table 3).

We were also interested in whether WSE varied by the total number of concerns (treatment problems plus life challenges). Did parents struggling with a higher number of problems and challenges also have a higher number of weekly service events to attend? They did; considering the number of treatment problems only, the average WSE increased for each additional treatment problem a parent had, beginning with 4.8 WSE for parents with no problems, and increasing to 10.5 for parents with 3 treatment problems $(\mathrm{r}[135]=.40, \mathrm{p}<.001)$. Considering the total number of concerns, the average mean WSE increases directly with the number of total concerns, with the exception of the highest number of concerns ( $\mathrm{n}=2$ for this category) (see Figure 1$)(\mathrm{r}[133]=.50, \mathrm{p}<.001)$.

\section{-- Figure 1 about here -}

\section{RQ 5: How well targeted are services ordered for reunifying families?}

Considering targeting by treatment problems individually, we found the majority of parents identified with a treatment problem were ordered to receive services treating that 
problem: $99 \%$ of the 104 parents with substance use issues were ordered to receive substance use treatment services; $86 \%$ of the 43 parents with domestic violence issues were ordered to received domestic violence treatment services, and $70.3 \%$ of the 37 parents with mental health issues were ordered to receive mental health treatment services. However, a substantial proportion of parents were ordered apparently unnecessary services: Six of the 35 parents (17.1\%) with no identified substance use issue were ordered to receive substance use treatment services, $26.6 \%$ of the 96 parents with no identified domestic violence issue were ordered to receive domestic violence treatment services, and $19.8 \%$ of the 102 parents with no identified mental health problem were ordered to receive mental health treatment services.

We next considered targeting by treatment problem constellation, examining whether all appropriate services were ordered. Excluding parents with no known treatment problem, about $86 \%$ of reunifying parents were ordered services targeting all of their identified problems. The rate was highest for parents with only a substance use problem -- all of these parents were ordered substance use services -- and lowest for the constellation of all three problems, as only 3 of these 8 parents (37.5\%) were ordered services targeting all the problems.

Finally, we examined whether parents were ordered services for problems they were not known to have, or whether only appropriate services were ordered. Excluding parents with all treatment problems, overall about $67 \%$ of parents were ordered only appropriate services. The rate was lowest for parents with no treatment problems - nine of these 20 parents (45\%) were ordered services only for problems they were known to have. When both aspects of targeting are taken into account, almost $60 \%$ of parents were 
ordered both all appropriate and only appropriate services, though the rate varied across the problem constellations (see Table 7).

-- Table 7 about here --

\section{Discussion}

As in other studies, results in this study suggest reunifying parents struggle with many challenges. While there was a proportion of families dealing with just one treatment problem, or even no treatment problem, when treatment problems and life challenges were combined, we saw that most families were struggling with multiple concerns overall. Additionally, both the number of service types ordered for parents, and the number of weekly service events at which attendance was required, were quite high. When we considered the relationship between weekly service events and total number of challenges, parents with more total concerns (problems and challenges combined) were ordered to attend more weekly service events on their case plans than were parents with fewer total concerns.

A high number of service requirements may cause logistical difficulties. Depending upon parents' economic, transportation, employment, and social support circumstances, as well as the degree to which they are struggling with other treatment problems and life challenges, getting to multiple service locations could be difficult. Additionally, the very problems that prompt the orders for treatment services may themselves hinder parents' ability to access services, including more general services like parenting classes or counseling. In some sense it seems logical that parents with more treatment problems need more assistance to treat those problems, and a well-intentioned caseworker may see a parent struggling with multiple problems and recommend services targeting all of them. 
However, it also seems likely that parents with more problems would have more difficulty accessing multiple services, and an "everything but the kitchen sink" approach could be problematic. At least one study has found negative associations between receipt of comprehensive intensive services and outcomes of time to reunification and re-entry (Brook \& McDonald, 2007).

For the commonly ordered services of parenting classes and counseling, an argument might be made that all parents could benefit from using these interventions. However, given logistical challenges inherent in accessing services and the multiple concerns confronting reunifying parents, a stronger argument might be made for excluding from case plans these more general services not directly treating the problems known to be interfering with parenting. Encumbering a parent's case plan with non-critical services that might be beneficial could very possibly complicate or challenge parents' ability to access those services that are known to be critically needed. More research is needed to determine whether general services of parenting classes and individual counseling are necessary for so many parents, or whether it would be no less effective to limit case plans to critically needed services, and reserve these types of general services for those instances in which there is an assessed critical need for them.

In terms of targeting, most parents with treatment problems of substance use, domestic violence and mental health were ordered services targeting those problems; the high rate was similar to other studies of the topic (Staudt \& Cherry, 2009). A substantial proportion of parents were ordered to receive services targeting problems they were not known to have. The accuracy of targeting varied somewhat across problem constellation, with parents at either end of the problem continuum - those with no identified problems or 
those with all three - least likely to have all appropriate and only appropriate services ordered. Overall, just under $60 \%$ of parents had all appropriate and only appropriate services ordered.

Accurate assessment of the family's needs and provision of services to address those needs is a crucial component of reunification. Studies have shown that when parents receive services targeting their problems, they are more likely to reunify (Cheng, 2010; Choi \& Ryan, 2007), so the relatively high rate at which parents are ordered services targeting their problems is positive. However, the fact that about $35 \%$ of parents were ordered to receive treatment services for problems they were not known to have, in the context of heavy service plans and highly challenged parents, is concerning. The ordering of treatment services that do not appear to be critically needed brings to mind findings from Smith's (2008) qualitative work on parental and caseworker perceptions of case plans, which found a "task oriented" and punitive understanding of case plans by both parties. Rather than burden highly challenged parents with the logistical task of accessing multiple services per week (and burdening the most highly challenged parents with the heaviest requirements), it might make sense to develop a service delivery strategy that reduces the burden of accessing services to its minimum, perhaps through a comprehensive program with services available on site, or colocation of some services, as suggested through an understanding of treatment problem constellations and associated life challenges. For example, domestic violence and housing problems were associated in this study; services addressing these issues could be co-located.

Finally, findings illuminate the important role substance use plays in the reunification process. It was the most common problem experience by reunifying parents; 
it seemed to complicate parents' circumstances with additional life challenges more than other treatment problems; and treatment services ordered for substance use resulted in a substantially greater number of requirements on parents' case plans. Two of the three services that often required attendance multiple times per week were substance use treatment interventions of drug testing and 12 step program attendance, so even parents struggling only with the single treatment problem of substance use had high weekly service attendance requirements. Thus a kind of "perfect storm" existed for parents with substance use issues: they had more life challenges than other parents, and higher case plan requirements as well. This combination may be contributing to the lower likelihood of reunification that has been found for substance using parents (Glisson, Bailey \& Post, 2000).

However, some research does suggest that substance using parents do better if they receive more services: In Grella, Needell, Shi \& Hser's (2009) study, clients in programs providing more education/employment services or family/children services were more likely to reunify than clients in programs providing fewer or less of these services; in Smith \& Marsh's (2002) study, participants who received more health and social services as part of their substance use treatment reported less substance use (in bivariate tests) and greater satisfaction with services (in multivariate models). However, in both studies it appears additional services were provided as part of the substance use treatment, and thus were likely to be combined or co-located with the substance use treatment. An integrated approach where all services are on-site and coordinated might be most sensible for these parents, as it would resolve the logistical challenge inherent in accessing multiple services without sacrificing the potential benefit of supplementary services such as parenting and 
counseling. The need for models of integrated services has been voiced by others

(Chambers \& Potter, 2008; Risley-Curtiss, Stromwall, Hunt, \& Teska, 2004).

\section{Limitations of the research}

These findings must be interpreted with caution. Data came from a single county and a single entry year cohort and thus cannot be generalized beyond that county and time period. While workers tended to note the presence of significant problems affecting parenting capacity in court reports, there was no systematic documentation process for this such as a checklist, and gradations of severity were not present. Life challenges, less directly related to parenting impairment than treatment problems, are likely to have been less consistently noted in the court report and thus were likely undercounted. Court reports are written by case workers, and reflect their perspective regarding parental circumstances. (However, as an issue of interest here was the degree to which services were targeted appropriately, the workers' perspective of client needs was relevant.) Finally services were occasionally ordered at a hearing subsequent to the initial jurisdictionaldispositional hearing, but the timing of this "staggering" of service delivery was not factored into the WSE measure. WSE is likely to be overestimated in some cases as a result.

In spite of these limitations, this descriptive study adds to the limited literature on reunifying parents' constellation of problems and life challenges, and illuminates an important consideration in understanding reunification from foster care related to case plan requirements and their relationship to parent problems. Further research exploring these issues in other jurisdictions, with more nuanced measures of problems and larger samples is needed. 


\section{References}

Alpert, L. (2005). Research review: Parents' service experience - a missing element in research on foster care outcomes. Child and Family Social Work, 10, 361-366. http://www.wiley.com/WileyCDA/WileyTitle/productCd-CFS.html

Antle, B.F., Barbee, A.P., Sullivan, D., Yankeelov, P., Johnson, L., \& Cunningham, M.R. (2007). The relationship between domestic violence and child neglect. Brief Treatment and Crisis Intervention, 7(4), 364-382. doi:10.1093/brief-treatment/mhm013

Bagdasaryan, S. (2005). Evaluating family preservation services: Reframing the question of effectiveness. Children and Youth Services Review, 27, 615-635. doi:10.1016/j.childyouth.2004.11.014

Besinger, B.A., Garland, A.F., Litrowlik, A.J., \& Landsverk, J.A. (1999). Caregiver substance abuse among maltreated children placed in out-of-home care. Child Welfare, 78(2), 221-239. http://www.cwla.org/articles/cwjabstracts.htm

Brook, J., \& McDonald, T. P. (2007). Evaluating the effects of comprehensive substance abuse intervention on successful reunification. Research on Social Work Practice, 17, (6), 664-673. doi:10.1177/1049731507300148.

Cash, S.J. \& Berry, M. (2002). Family characteristics and child welfare services: Does the assessment drive service provision? Families in Society: The Journal of Contemporary Social Services, 83(5/6), 499-507. http://www.familiesinsociety.org/

Chambers, R.M. \& Potter, C.C. (2008). The match between family needs and services for high-risk neglecting families. Journal of Public Child Welfare, 2(2), 229-252. doi: $10.1080 / 15548730802312750$. 
Cheng, T.C. (2010). Factors associated with reunification: A longitudinal study of long-term foster care. Children and Youth Services Review, 32, 1311-1316. doi:10.1016/j.childyouth.2010.04.023

Children's Bureau, ACYF, ACF, U.S. Department of Health and Human Services (n.d.). Child welfare outcomes 2006-2009 report to Congress. Retrieved from: http://www.acf.hhs.gov/programs/cb/pubs/cwo06-09/cwo06-09.pdf.

Child Welfare Information Gateway (2010). Case planning for families involved with child welfare agencies. U.S. Department of Health and Human Services, Administration for Children and Families, Administration on Children Youth and Families, Children's Bureau.

Child Welfare Information Gateway (2006). Family reunification: What the evidence shows. U.S. Department of Health and Human Services, Administration for Children and Families, Administration on Children Youth and Families, Children's Bureau.

Choi, S. \& Ryan, J.P. (2007). Co-occurring problems for substance abusing mothers in child welfare: Matching services to improve family reunification. Children and Youth Services Review, 29, 1395-1410. doi:10.1016/j.childyouth.2007.05.013.

Courtney, M., McMurtry, S.L., \& Zinn, A. (2004). Housing problems experienced by recipients of child welfare services. Child Welfare, 83(5), 393-422. http://www.cwla.org/articles/cwjabstracts.htm Glisson, C., Bailey, J.W., \& Post, J.A. (2000). Predicting the time children spend in state custody. Social Service Review, 74(2), 253-280. doi:10.1086/514479 
Green, B. L., Rockhill, A., \& Furrer, C. (2007). Does substance abuse treatment make a difference for child welfare case outcomes? A statewide longitudinal analysis. Children and Youth Services Review, 29, 460-473.

doi:10.1016/j.childyouth.2006.08.006

Grella, C.E., Needell, B., Shi, Y., \& Hser, Y. (2009). Do drug treatment services predict reunification outcomes of mothers and their children in child welfare? Journal of Substance Abuse Treatment, 36, 278-293. doi: 10.1016/j.jsat.2008.06.010

Lewandowski, C.A. \& Pierce, L. (2004). Does family-centered out-of-home care work? Comparison of a family-centered approach and traditional care. Social Work Research, 28(3), 143-151. doi:10.1093/swr/28.3.143

Marcenko, M.O., Lyons, S.J., \& Courtney, M. (2011). Mothers' experiences, resources and needs: The context for reunification. Children and Youth Services Review, 33, 431438. doi:10.1016/j.childyouth.2010.06.020.

Needell, B., Webster, D., Armijo, M., Lee, S., Dawson, W., Magruder, .... \& Nuttbrock, A. (2012). Child Welfare Services Reports for California. Retrieved from University of California at Berkeley Center for Social Services Research website. URL: <http://cssr.berkeley.edu/ucb_childwelfare>

Risley-Curtiss, C., Stromwall, L.K., Hunt, D.T., \& Teska, J. Identifying and reducing barriers to reunification for seriously mentally ill parents involved in child welfare cases. Families in Society, 85(1), 107-118. http://www.familiesinsociety.org/ 
Ryan, J P., Marsh, J C., Testa, M F., \& Louderman, R. (2006). Integrating substance abuse treatment and child welfare services: Findings from the Illinois Alcohol and Other Drug Abuse Waiver Demonstration. Social Work Research, 30 (2), 95-107. doi:10.1093/swr/30.2.95

Ryan, J.P. \& Schuerman, J.R. (2004). Marching family problems with specific family presentation services: A study of service effectiveness. Children and Youth Services Review, 26, 347-372. doi:10.1016/j.childyouth.2004.01.004

Smith, B.D. (2003). How parental drug use and drug treatment compliance relate to family reunification. Child Welfare, 82(3), 335-365. http://www.cwla.org/articles/cwjabstracts.htm

Smith, B.D. (2008). Child welfare service plan compliance: Perceptions of parents and caseworkers. Families in Society, 89(4), 521-532. doi: 10.1016/1044-394.3818.

Smith, B.D. \& Marsh, J.C. (2002). Client-service matching in substance abuse treatment for women with children. Journal of Substance Abuse Treatment, 22, 161-168. doi:10.1016/S0740-5472(02)00229-5

Staudt. M. \& Cherry, D. (2009). Mental health and substance use problems of parents involved with child welfare: Are services offered and provided? Psychiatric Services, 60(1), 56-60. doi:10.1176/appi.ps.60.1.56

Stromwall, L.K., Larson, N.C., Nieri, T., Holley, L.C., Topping, D., Castillo, J., \& Ashford, J.B. (2008). Parents with co-occurring mental health and substance abuse conditions involved with child protection services: Clinical profile and treatment needs. Child Welfare, 87(3), 95-113. http://www.cwla.org/articles/cwjabstracts.htm 
Weber, K., Morrison, S., Navarro, S., Spigner, C., \& Pence, E. (2010). Positive outcomes for all: Using an Institutional Analysis to identify and address African American children's low reunification rates and long-term stays in Fresno county's foster care system. Center for the Study of Social Policy, Washington, D.C. Retrieved from http://www.cssp.org/pdfs/positive_outcomes_fresno_co_institutional_analysis.pdf Wells, K. \& Shafran, R. (2005). Obstacles to employment among mothers of children in foster care. Child Welfare, 84(1), 67-96. http://www.cwla.org/articles/cwjabstracts.htm 


\section{APPENDIX A: Tables}


Targeting Reunification Services

Table 1

Sample Demographics

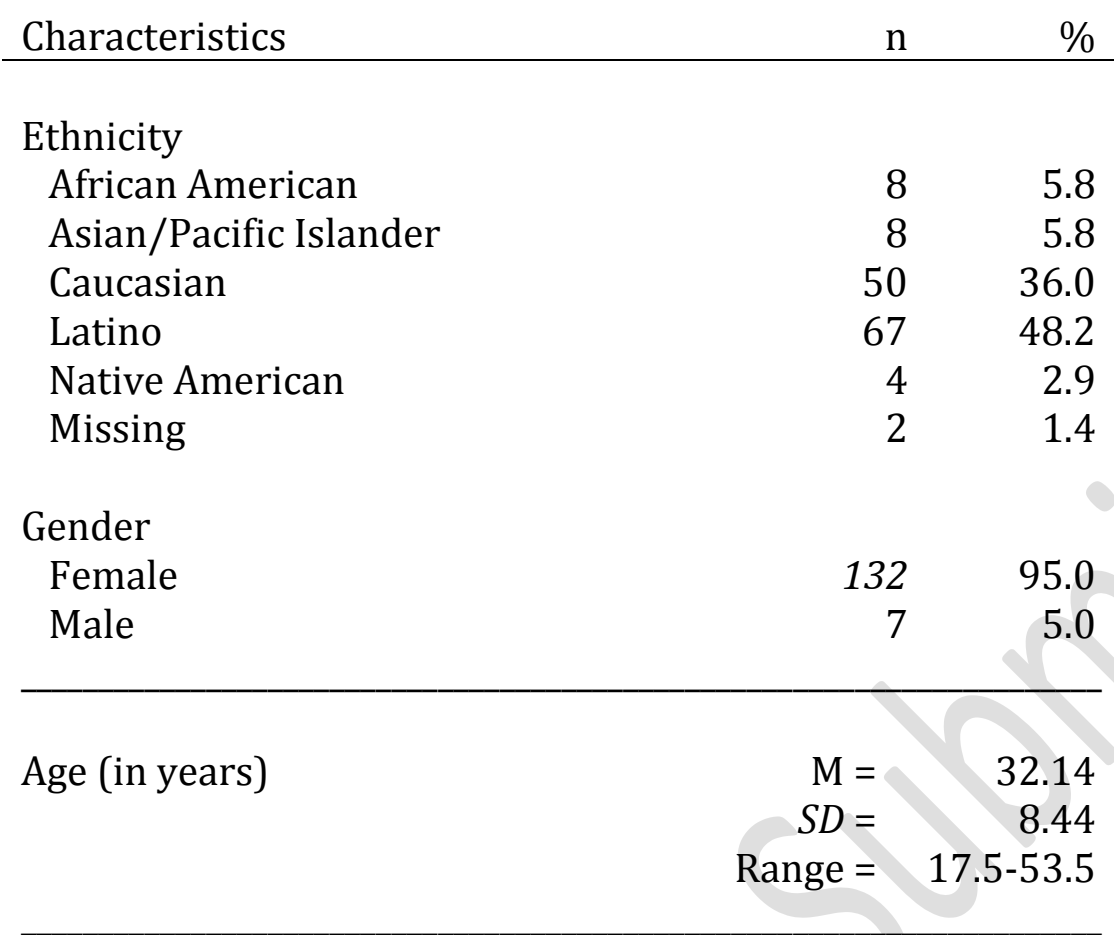

Note. Total sample $\mathrm{N}=139$ 
Targeting Reunification Services

Table 2

Percentage of Parents with Listed Problems During Case

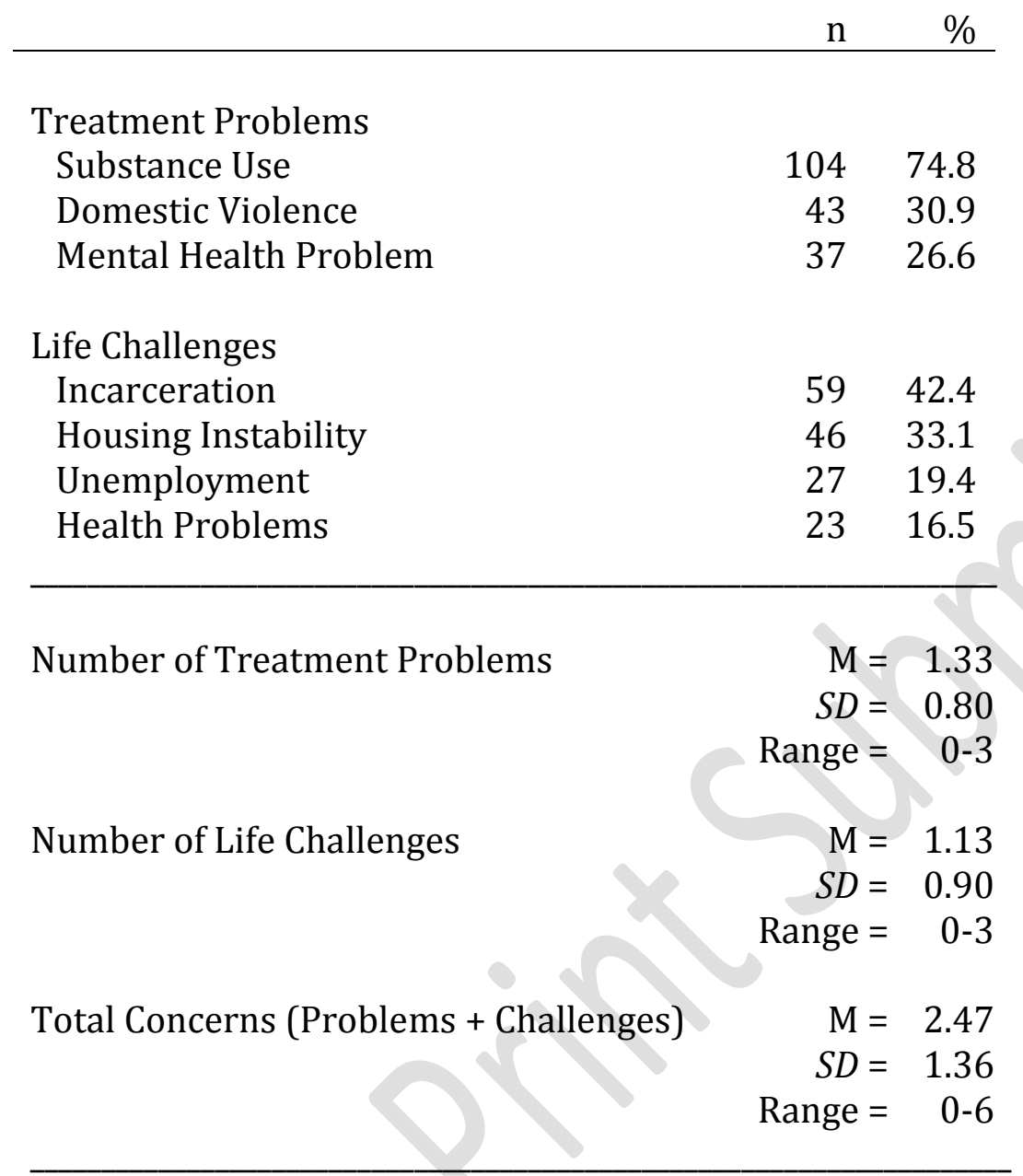

| Note. Total sample $\mathrm{N}=139$ 
Targeting Reunification Services

Table 3

Treatment Problem Constellations and Average WSE

\begin{tabular}{lrrr} 
& $\mathrm{n}$ & $\%$ & $\begin{array}{r}\text { Avg } \\
\text { WSE }\end{array}$ \\
\hline SA only & 47 & 33.8 & 8.47 \\
SA \& DV & 27 & 19.4 & 9.78 \\
SA \& MH & 21 & 15.1 & 8.40 \\
SA \& DV \& MH & 8 & 5.8 & 10.50 \\
DV only & 7 & 5.0 & 4.88 \\
MH only & 6 & 4.3 & 4.67 \\
MH \& DV & 1 & 0.7 & 4.00 \\
No Clinical Problem noted & 20 & 14.4 & 4.80 \\
Missing & 2 & 1.4 & -- \\
TOTAL & 139 & 100.0 & 7.92 \\
\hline
\end{tabular}

Note SA = Substance Use problem, DV = Domestic Violence problem, $\mathrm{MH}=$ Mental Health problem .

Table 4

Rate of Life Challenges by Presence of Treatment Problem

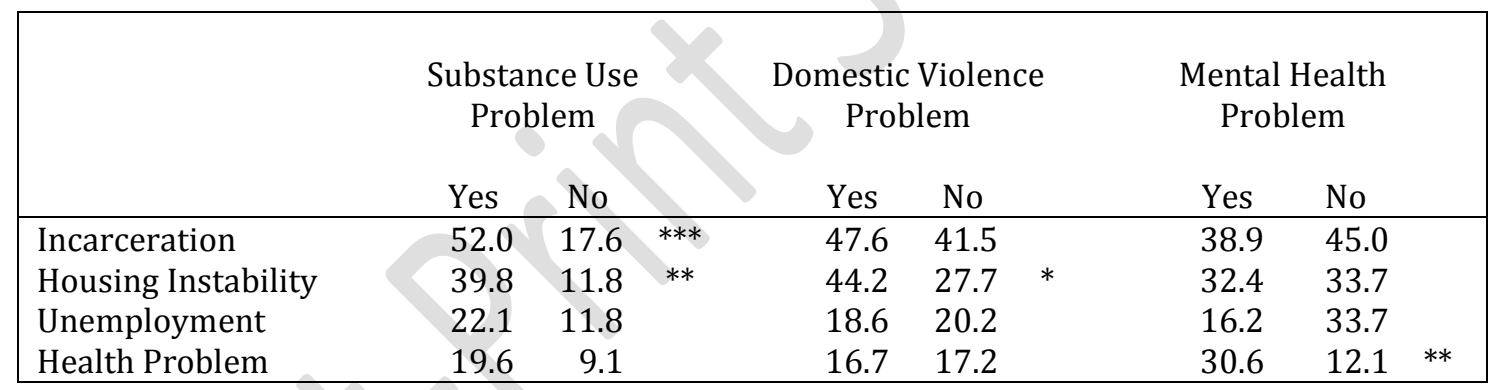

$*=\mathrm{p}<.05 ;{ }^{* *}=\mathrm{p}<.01 ;{ }^{* * *}=\mathrm{p}<.001$ 
Targeting Reunification Services

Table 5

Proportion of Parents Ordered to Each Service Type

\begin{tabular}{lrr} 
Service & $\mathrm{n}$ & $\%$ \\
\hline & & \\
Any Substance Use Service & 110 & 79.1 \\
Substance Use Assessment & 88 & 63.3 \\
Testing & 110 & 79.1 \\
Inpatient & 34 & 24.5 \\
Outpatient & 68 & 48.9 \\
12 Step Program & 94 & 67.6 \\
Aftercare program & 29 & 20.9 \\
Other type & 10 & 7.2 \\
& & \\
Any Domestic Violence Service & 62 & 44.6 \\
DV Assessment & 10 & 7.2 \\
Batterers Program & 3 & 2.2 \\
Victims Program & 54 & 38.8 \\
& & \\
Any Mental Health Service & 45 & 33.1 \\
Psychological Evaluation & 33 & 23.7 \\
Medication/Med management & 12 & 8.6 \\
Psycho/Educational Group & 2 & 1.4 \\
Other Psychological Service & 7 & 5.0 \\
& & \\
Any Counseling Service & 123 & 88.5 \\
Individual Counseling & 122 & 87.8 \\
Family Therapy & 13 & 9.4 \\
Couples & 3 & 2.2 \\
& & \\
Any Parenting Service & 131 & 94.2 \\
Basic & 86 & 61.9 \\
Advanced & 12 & 8.6 \\
Parenting without Violence & 35 & 25.2 \\
Other type & 24 & 17.3 \\
Visitation & & \\
& 134 & 96.4 \\
\hline & & \\
\hline
\end{tabular}

Note SA = Substance Use problem, DV = Domestic Violence problem, $\mathrm{MH}=$ Mental Health problem. 
Targeting Reunification Services

Table 6

Attendance Required per Week by Service

\begin{tabular}{lrr} 
& $\#$ & \multicolumn{1}{c}{$\%$} \\
\hline & 110 & 100.00 \\
Drug Testing & 26 & 23.6 \\
Once or less per week & 80 & 72.7 \\
Twice per week & 4 & 3.6 \\
Three or more times per week & & \\
& 94 & 100.0 \\
12 Step Meeting Attendance & 21 & 22.3 \\
Once or less per week & 35 & 37.2 \\
Twice per week & 38 & 40.5 \\
Three or more times per week & & \\
& 134 & 100.00 \\
Visitation & 71 & 53.3 \\
Once or less per week & 61 & 45.2 \\
Twice per week & 2 & 1.5 \\
Three or more times per week & &
\end{tabular}

Table 7

Service Targeting by Problem Constellation

\begin{tabular}{|c|c|c|c|c|c|c|c|}
\hline & \multirow[b]{2}{*}{$\mathrm{N}$} & \multicolumn{2}{|c|}{$\begin{array}{l}\text { All necessary } \\
\text { services ordered }\end{array}$} & \multicolumn{2}{|c|}{$\begin{array}{l}\text { No unnecessary } \\
\text { services ordered }\end{array}$} & \multicolumn{2}{|c|}{$\begin{array}{c}\text { All and only } \\
\text { necessary services } \\
\text { ordered }\end{array}$} \\
\hline & & $\mathrm{n}$ & $\%$ & $\mathrm{n}$ & $\%$ & $\mathrm{n}$ & $\%$ \\
\hline SA only & 47 & 47 & 100.0 & 31 & 66.0 & 31 & 66.0 \\
\hline SA \& DV & 27 & 23 & 85.2 & 22 & 81.5 & 19 & 70.4 \\
\hline SA \& MH & 21 & 16 & 76.2 & 16 & 76.2 & 11 & 52.4 \\
\hline SA \& DV \& MH & 8 & 3 & 37.5 & -- & -- & 3 & 37.5 \\
\hline DV only & 7 & 6 & 85.7 & 4 & 57.1 & 4 & 57.1 \\
\hline MH only & 6 & 5 & 83.3 & 4 & 66.7 & 4 & 66.7 \\
\hline $\mathrm{MH} \& \mathrm{DV}$ & 1 & 1 & 100.0 & 1 & 100.0 & 1 & 100.0 \\
\hline No Clinical Problem noted & 20 & -- & -- & 9 & 45.0 & 9 & 45.0 \\
\hline TOTAL & 137 & $101 / 117$ & 86.3 & $87 / 129$ & 67.4 & $82 / 137$ & 59.8 \\
\hline
\end{tabular}

Note SA = Substance Use problem, DV = Domestic Violence problem, MH = Mental Health problem. 
Targeting Reunification Services

APPENDIX B: Figures 
Targeting Reunification Services

\section{Figure 1}

Average Weekly Service Events (WSE) by Total Concerns

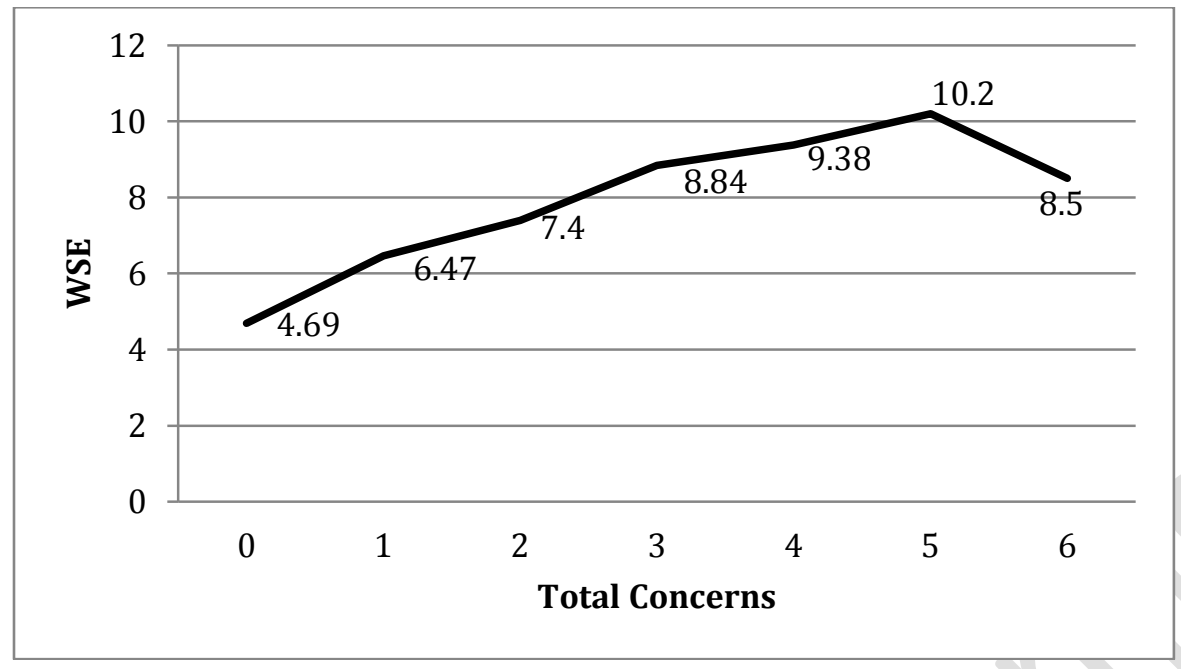

